\title{
Coyotes as Reservoirs for Onchocerca lupi, United States, 2015-2018
}

Chandler C. Roe, Hayley Yaglom, April Howard, Jennifer Urbanz, Guilherme G. Verocai, Lela Andrews,
Veronica Harrison, Riley Barnes, Ted Lyons, Jolene R. Bowers, David M. Engelthaler

The Onchocerca lupi nematode infects dogs, cats, and humans, but whether it can be spread by coyotes has been unknown. We conducted surveillance for $O$. lupi nematode infection in coyotes in the southwestern United States. We identified multiple coyote populations in Arizona and New Mexico as probable reservoirs for this species.

C nchocerca lupi is a species of zoonotic, filarial nematode that causes onchocerciasis in dogs, cats, and humans. It was first described in 1967 in Georgia, then part of the USSR, in the periocular tissues of a wolf (Canis lupus lupus) (1) and has been reported in dogs (C. lupus domesticus). Since 2013, increased detection of O. lupi infections in dogs and humans in the United States and Europe has renewed interest in this parasite, its geographic distribution, and the range of its natural hosts (2).

The geographic distribution and prevalence of the O. lupi nematode in the United States is unknown. US veterinarians are not required to report O. lupi infections in canines, making it difficult to identify the parasite's geographic distribution. The first documented case of O. lupi infection in the United States affected a dog in California in 1991 (3); since then, $O$. lupi infections have been reported in dogs, cats, and humans in Arizona, California, Colorado, New Mexi-

Author affiliations: Translational Genomics Research Institute, Flagstaff, Arizona, USA (C.C. Roe, H. Yaglom, V. Harrison, R. Barnes, T. Lyons, J.R. Bowers, D.M. Engelthaler); Northern Arizona University, Flagstaff (C.C. Roe, L. Andrews); Arizona Department of Health Services, Phoenix, Arizona, USA

(H. Yaglom); Arizona Game and Fish Department, Phoenix

(A. Howard); Eye Care for Animals, Scottsdale, Arizona, USA

(J. Urbanz); Texas A\&M University, College Station, Texas, USA

(G.G. Verocai); University of Georgia, Athens, Georgia, USA

(G.G. Verocai)

DOI: https://doi.org/10.3201/eid2612.190136 co, Texas, and Utah $(2,4,5,6)$. This parasitic nematode is now endemic in domesticated canines in the southwestern United States (7). Reports of O. lupi infection in Canada (Alberta and Prince Edward Island) (7) associated with dog importation from the southwestern United States and travel of US companion animals suggest an anthropogenic spread of the O. lupi nematode. Whether wild canids, including coyotes (C. latrans), might be reservoirs for the O. lupi nematode is unknown.

Because of the growing number of O. lupi infections in canines and humans, public health officials must understand the prevalence and distribution of this parasite in wildlife. Toward that goal, we investigated coyote populations in Arizona, New Mexico, and Nevada as potential primary hosts and natural reservoirs for the O. lupi nematode.

\section{The Study}

From December 2015 through July 2018, we collected skin tissue samples from coyotes harvested for predation management conducted by the Arizona Game and Fish Department, and from hunters in Arizona, New Mexico, and Nevada. We did not euthanize any coyotes for the specific purpose of this study. Skin tissue from the interocular frontal area of the animal's head was removed and stored in $80 \%$ ethanol until we extracted the DNA. We screened 707 DNA sequences for an O. lupi cytochrome c oxidase (COI) gene (8) using SYBR Green-real-time PCR on a QuantStudio 7 Flex Real Time PCR System (Thermo Fisher Scientific, https://www.thermofisher.com). We used DNA from an adult worm from an infected dog in northern Arizona as a positive control (GenBank accession no. MT878136). We included a no-template control in every real-time PCR reaction plate. We compared the product's melting curve to the positive control using a dissociation curve. We prepared every sample that had a melting curve resembling that of the positive 
Table. Coyotes tested for Onchocerca lupi nematodes, United States, 2015-2018

\begin{tabular}{|c|c|c|c|c|c|c|}
\hline \multirow[b]{2}{*}{ Location } & \multirow[b]{2}{*}{ No. samples } & \multirow{2}{*}{$\begin{array}{l}\text { No. (\%) positive } \\
\text { samples }\end{array}$} & \multicolumn{2}{|c|}{ Coyote sex } & \multicolumn{2}{|c|}{ Coyote age group } \\
\hline & & & $\mathrm{M}$ & $\mathrm{F}$ & Adult & Youth \\
\hline \multicolumn{7}{|l|}{ Arizona } \\
\hline Coconino & 189 & $5(2.7)$ & 97 & 92 & 177 & 12 \\
\hline Apache & 106 & $10(9.4)$ & 56 & 50 & 88 & 18 \\
\hline Yavapai & 86 & $1(1.2)$ & 49 & 37 & 78 & 8 \\
\hline Cochise & 75 & 0 & 44 & 31 & 66 & 9 \\
\hline Mohave* & 56 & $1(1.8)$ & 29 & 26 & 53 & 3 \\
\hline Navajo* & 48 & $17(35.4)$ & 31 & 16 & 45 & 3 \\
\hline Graham & 48 & 0 & 24 & 24 & 46 & 2 \\
\hline Maricopa & 42 & $1(2.4)$ & 19 & 23 & 32 & 10 \\
\hline La Paz & 14 & $1(7.1)$ & 5 & 9 & 12 & 2 \\
\hline Pima & 6 & 0 & 2 & 4 & 6 & 0 \\
\hline Pinal & 3 & 0 & 1 & 2 & 3 & 0 \\
\hline Yuma & 1 & 0 & 1 & 0 & 1 & 0 \\
\hline Unknownt & 1 & 0 & 0 & 1 & 1 & 0 \\
\hline Unknownt & 1 & 0 & 0 & 1 & 1 & 0 \\
\hline \multicolumn{7}{|l|}{ New Mexico } \\
\hline Catron & 7 & 0 & 5 & 2 & 6 & 1 \\
\hline McKinley & 1 & 0 & 0 & 1 & 1 & 0 \\
\hline San Juan & 4 & 0 & 1 & 3 & 4 & 0 \\
\hline Torrence & 4 & 0 & 3 & 1 & 3 & 1 \\
\hline Tucamari & 3 & 0 & 1 & 2 & 3 & 0 \\
\hline Quay & 3 & 0 & 3 & 0 & 3 & 0 \\
\hline Hildago & 2 & $1(50.0)$ & 1 & 1 & 2 & 0 \\
\hline Zuni & 1 & 0 & 1 & 0 & 1 & 0 \\
\hline \multicolumn{7}{|l|}{ Nevada } \\
\hline Elko & 4 & 0 & 3 & 1 & 4 & 0 \\
\hline Nye & 2 & 0 & 1 & 1 & 2 & 0 \\
\hline
\end{tabular}

*Mohave and Navajo Counties each had 1 sample for which host sex was not recorded.

†2 samples from Arizona did not have a recorded county.

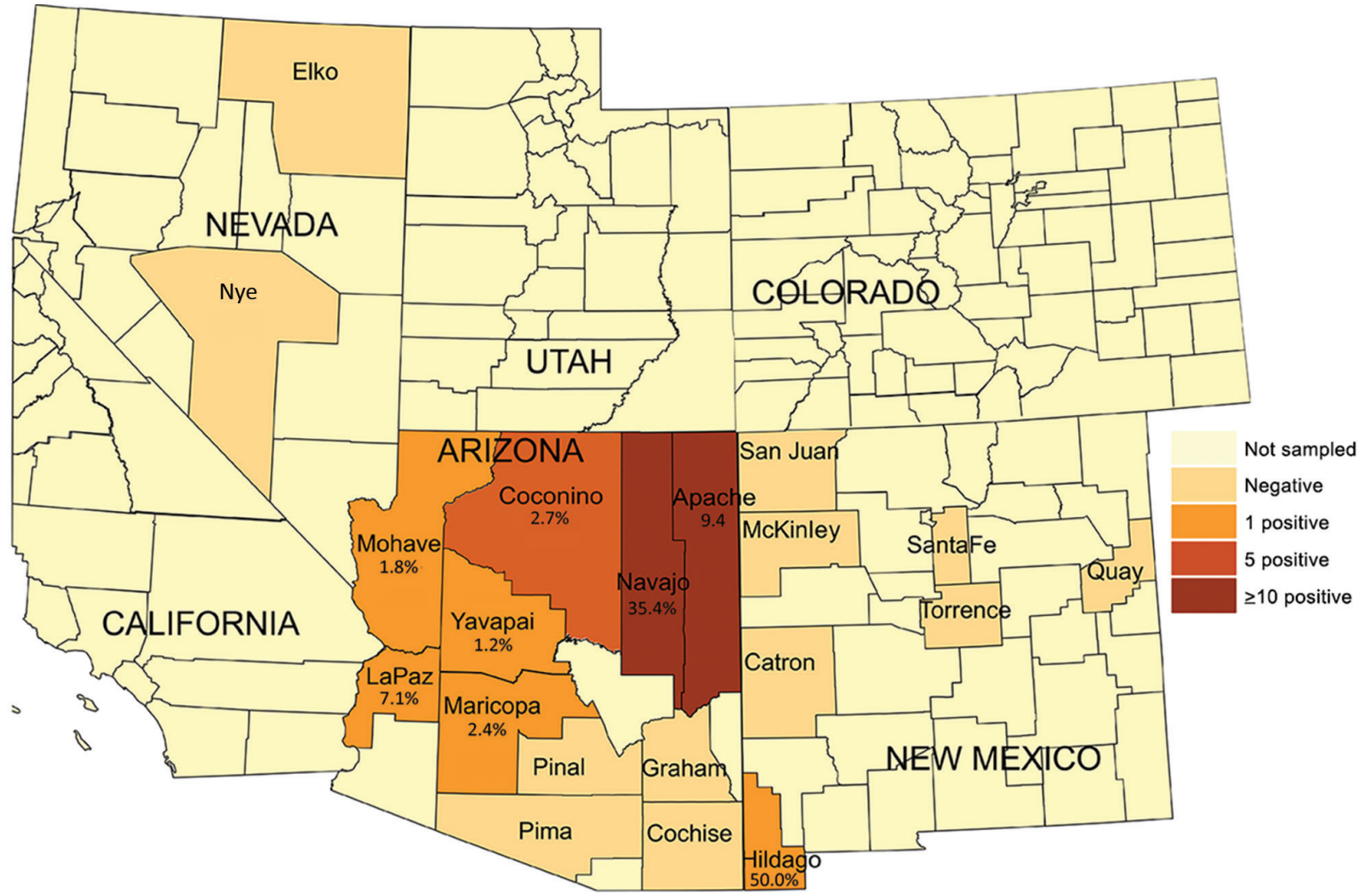

Figure 1. Number of Onchocerca lupi nematode-positive coyotes collected, southwestern United States, 2015-2018. Positivity rates are provided for each county with $O$. Iupi-positive coyotes. 
control for amplicon sequencing using neat DNA and Illumina (https://www.illumina.com) technologies.

Thirty-seven (5.2\%) samples from 8 counties in Arizona and New Mexico (Table 1) had sequences that aligned with the reference gene. Of these sam- ples, 36 were from Arizona and 1 was from Hildago County, New Mexico. In Arizona, the highest prevalences of O. lupi infection were in Navajo County (17 [35.4\%] positive coyotes) and Apache County (10 $[9.4 \%]$ ) (Figure 1). Coconino County had the third

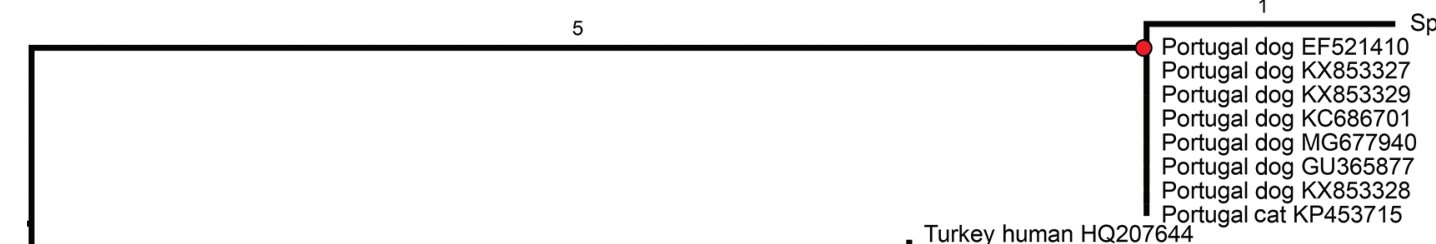

Turkey human HQ2076
Greece dog KC686702

Spain dog KX132091

Romania dog KJ403844

Hungary dog EF521408

Romania dog KJ403844

Greece dog EF521409

USA dog California KC763785

USA dog New Mexico JX183106

USA dog Las Vegas NV JX080028

USA dog Palmdale CA JX080029

USA dog Mancos CO JX080030

USA dog Kanaab UT JX080031

USA dog New Mexico KP283476

USA dog Minnesota KP283477

USA dog KX853332

USA dog KX853330

USA dog KX853331

USA cat Utah JF758473

USA cat Utah JF758474

USA cat Utah JF758475

USA coyote 2017-316 Yavapai AZ

USA coyote 2017-311 Coconino AZ

USA coyote 2017-308 NA

USA coyote 2017-307 LaPaz AZ

USA coyote 2017-306 Coconino AZ

USA coyote 2017-305 Coconino AZ

USA coyote 2017-301 Coconino AZ

USA coyote 2017-296 Navajo AZ

USA coyote 2017-291 Navajo AZ

USA coyote 2017-281 Maricopa AZ

USA coyote 2017-280 Navajo AZ

USA coyote 2017-274 Navajo AZ

USA coyote 2017-273 Navajo AZ

USA coyote 2017-270 Coconino AZ

USA coyote 2017-263 Navajo AZ

USA coyote 2017-262 Hildago NM

USA coyote 2017-258 Navajo AZ

USA coyote 2017-250 Navajo AZ

USA coyote 2017-247 Navajo AZ

USA coyote 2017-245 Navajo AZ

USA coyote 2017-244 Navajo AZ

USA coyote 2017-233 Apache AZ

USA coyote 2017-232 Navajo AZ

USA coyote 2017-227 Navajo AZ

USA coyote 2017-221 Navajo AZ

USA coyote 2017-214 Navajo AZ

USA coyote 2017-199 Navajo AZ

USA coyote 2017-194 Navajo AZ

USA coyote 2017-181 Apache AZ

USA coyote 2017-041 Apache AZ

USA coyote 2017-035 Apache AZ

USA coyote 2017-034 Apache AZ

USA coyote 2017-031 Apache AZ

USA coyote 2017-027 Apache AZ

USA coyote 2017-026 Apache AZ

USA coyote 2017-025 Apache AZ

USA coyote 2017-023 Apache AZ

USA human $A Z$

USA human AZ

USA dog Kayenta AZ

USA dog Utah

USA dog Yuma AZ

0.002

USA dog Flagstaff AZ

Figure 2. Rooted maximum-likelihood phylogenetic tree based on the cytochrome oxidase c gene sequence from 73 Onchocerca lupi nematode samples, including 43 newly obtained samples from 37 coyotes, 4 dogs, and 2 humans, southwestern United States, 2015-2018. This analysis covers 432 bases. Branch lengths indicate the number of single-nucleotide polymorphisms; red dots indicate bootstrap values $>99$; blue dots indicate bootstrap values $<65$. Countries of collection, host species, and year of collection are indicated. Newly sequenced specimens are in bold. Scale bar indicates number of nucleotide substitutions per site. 
highest number (5) of coyotes that tested positive for the O. lupi nematode but a lower positivity rate $(2.7 \%)$ than other counties. For example, in Hidalgo County we sampled only 2 coyotes, 1 of which tested positive.

We produced a phylogenetic tree of our $43 \mathrm{COI}$ sequences (including 4 that were isolated from infected dogs and 2 from humans [GenBank accession nos. MT878134-9]) in addition to 30 O. lupi COI genes on GenBank spanning 432 total bases containing 12 single-nucleotide polymorphisms (SNPs) (Figure 2) using IQTREE version 1.6.9 (9) software with 1,000 bootstrap replicates. Examining only this region of the COI gene, we determined the US samples (from dogs, cats, coyotes, and humans) clustered within a single clade with dog samples from Germany, Romania, and Greece. Within this clade, we detected no SNP differences. This clade was separated from a sample from Hungary by 1 SNP and from a single clade containing a human isolate from Turkey and a dog sample from Greece by 1 SNP.

\section{Conclusions}

O. lupi infection has been reported mainly in domestic dogs and cats in the southwestern United States $(4,2)$. However, international transportation (purchasing, adopting, and exporting) of dogs from that area has introduced this parasite into environments to which it is not endemic $(7,10)$. We hypothesize coyotes are reservoirs for the O. lupi nematode and could spread this parasite throughout the southwestern United States.

We consider the probable importance of coyotes as natural reservoirs and dispersal agents. In the United States, the average home territory covered by a resident coyote population (either a pack or lone coyote) is $5-41 \mathrm{~km}^{2}$, whereas solitary transient coyote territories are up to $155 \mathrm{~km}^{2}(11,12)$. The large geographic range and widespread occurrence of not only coyotes, but also the putative black fly vector (Diptera: Simuliidae) (13), might facilitate the spread and establishment of the $O$. lupi nematode in the southwestern United States. Furthermore, many North American wild canids, such as wolves and foxes, have never been assessed for the O. lupi nematode but also should be considered as potential reservoirs. Although the O. lupi nematode is only endemic to the southwestern United States, without appropriate surveillance and mitigation strategies it might spread across the United States and into Canada and Mexico. We are not aware of any reports of O. lupi nematodes in Mexico; however, we identified a coyote that tested positive for O. lupi infection in Hildago County, which borders Mexico. Increasing surveil- lance in nearby counties upon identification of O. lupi nematode-positive coyotes would be prudent. Furthermore, the overlap of rural human residences with coyote and black fly populations probably increases the risk for human exposure.

In summary, canine onchocerciasis is an ongoing emerging infectious threat to wildlife, companion animals, and humans. The expanding range to which the O. lupi nematode is endemic, coupled with increased incidence of onchocerciasis in humans and canines in the southwestern United States, reinforces the need to understand, respond to, and potentially mitigate this threat. This understanding will enable the development of surveillance and mitigation strategies, determine the risk of spread to nonendemic regions, and identify human populations at high risk of infection.

\section{Acknowledgments}

We thank Yvonne Qvarnstrom for providing 2 O. lupi nematode-positive samples from 2 humans in Arizona that were included in this study. We also acknowledge Laura Adams for her contribution.

This study was funded in part by contract 200-2016-92313 with the Centers for Disease Control and Prevention under its Advanced Molecular Detection Initiative.

\section{About the Author}

Ms. Roe is a research coordinator at the Pathogen and Microbiome Institute and a doctoral student in the School of Informatics and Computing at Northern Arizona University. Her primary research interests include pathogen genomics of parasites, fungi, and bacteria.

\section{References}

1. Rodonaja TE. A new species of nematode, Onchocerca lupi $\mathrm{n}$. sp., from Canis lupus cubanensis. Soobshchenyia Akad Nuak Gruz Ssr. 1967;45:715-9.

2. Cantey PT, Weeks J, Edwards M, Rao S, Ostovar GA, Dehority W, et al. The emergence of zoonotic Onchocerca lupi infection in the United States - a case-series. Clin Infect Dis. 2016;62:778-83. https://doi.org/10.1093/cid/civ983

3. Orihel TC, Ash LR, Holshuh HJ, Santenelli S. Onchocerciasis in a California dog. Am J Trop Med Hyg. 1991;44:513-7. https://doi.org/10.4269/ajtmh.1991.44.513

4. McLean NJ, Newkirk K, Adema CM. Canine ocular onchocerciasis: a retrospective review of the diagnosis, treatment, and outcome of 16 cases in New Mexico (2011-2015). Vet Ophthalmol. 2017;20:349-56. https://doi.org/10.1111/vop.12433

5. Eberhard ML, Ostovar GA, Chundu K, Hobohm D, Feiz-Erfan I, Mathison BA, et al. Zoonotic Onchocerca lupi infection in a 22-month-old child in Arizona: first report in the United States and a review of the literature. Am J Trop Med Hyg. 2013;88:601-5. https:/ / doi.org/ 10.4269/ajtmh.12-0733 
6. Labelle AL, Maddox CW, Daniels JB, Lanka S, Eggett TE, Dubielzig RR, et al. Canine ocular onchocercosis in the United States is associated with Onchocerca lupi. Vet Parasitol. 2013;193:297-301. https://doi.org/10.1016/ j.vetpar.2012.12.002

7. Verocai GG, Conboy G, Lejeune M, Marron F, Hanna P, MacDonald E, et al. Onchocerca lupi nematodes in dogs exported from the United States into Canada. Emerg Infect Dis. 2016;22:1477-9. https:// doi.org/10.3201/eid2208.151918

8. Hassan HK, Bolcen S, Kubofcik J, Nutman TB, Eberhard ML, Middleton K, et al. Isolation of Onchocerca lupi in dogs and black flies, California, USA. Emerg Infect Dis. 2015;21:789-96. https://doi.org/10.3201/eid2105.142011

9. Nguyen L-T, Schmidt HA, von Haeseler A, Minh BQ IQ-TREE: a fast and effective stochastic algorithm for estimating maximum-likelihood phylogenies. Mol Biol Evol. 2015;32:268-74. https:// doi.org/10.1093/molbev/msu300

10. Colella V, Lia RP, Di Paola G, Cortes H, Cardoso L,

Otranto D. International dog travelling and risk for zoonotic
Onchocerca lupi. Transbound Emerg Dis. 2018;65:1107-9. https://doi.org/10.1111/tbed.12842

11. Gehrt SD, Anchor C, White LA. Home range and landscape use of coyotes in a metropolitan landscape: conflict or coexistence? J Mammal. 2009;90:1045-57. https://doi.org/10.1644/08-MAMM-A-277.1

12. Howard VW, Delfrate GG. Home ranges and movements of coyotes in the northern Chihuahuan desert. 1991 [cited 2019 Jan 4]. https:/ / digitalcommons.unl.edu/cgi/view content.cgi? article $=1014 \&$ context $=$ gpwdcwp

13. Adler PH, Currie DC, Wood M, Idema RM, Zettler LW. The black flies (Simuliidae) of North America. Ithaca (NY): Cornell University Publishing; 2004.

Address for correspondence: Chandler Roe, Northern Arizona University, Pathogen and Microbiome Institute, 1395 S. Knoles Dr, Bldg 56, Ste 210, Flagstaff, AZ 86011, USA; email: chandler.roe@nau.edu

\section{Emerging Infectious Diseases Spotight Topics}
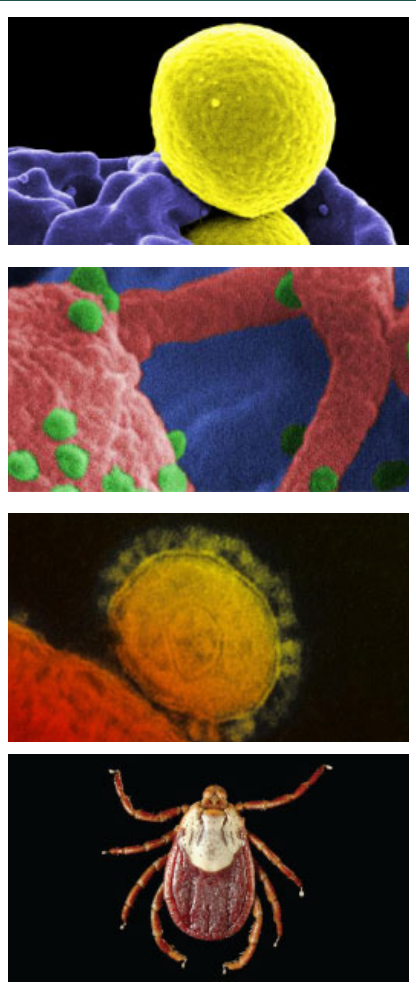
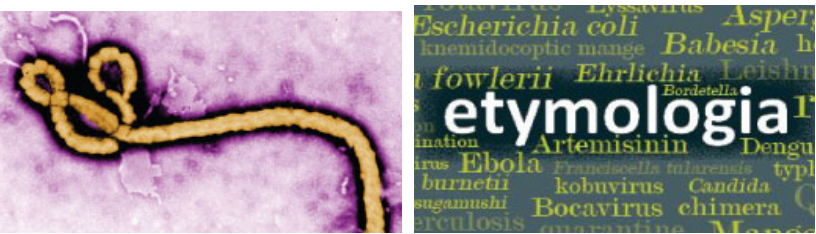

Antimicrobial resistance • Ebola Etymologia Food safety • HIV-AIDS Influenza • Lyme disease • Malaria MERS • Pneumonia • Rabies • Ticks Tuberculosis • Coronavirus • Zika
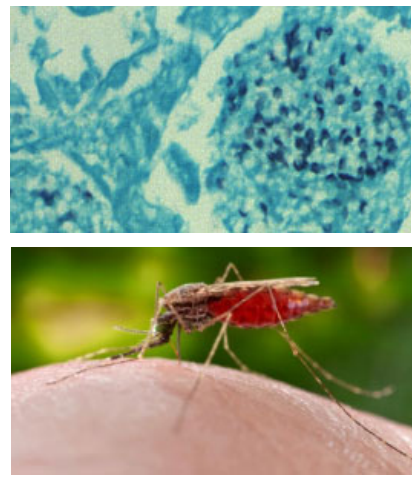
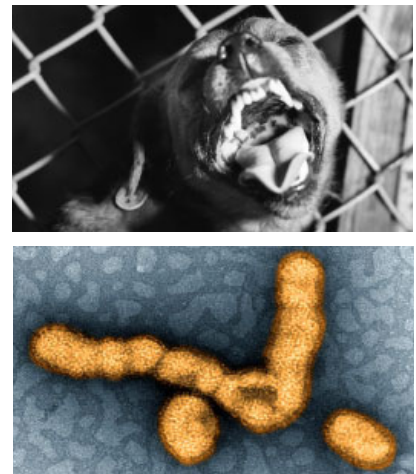
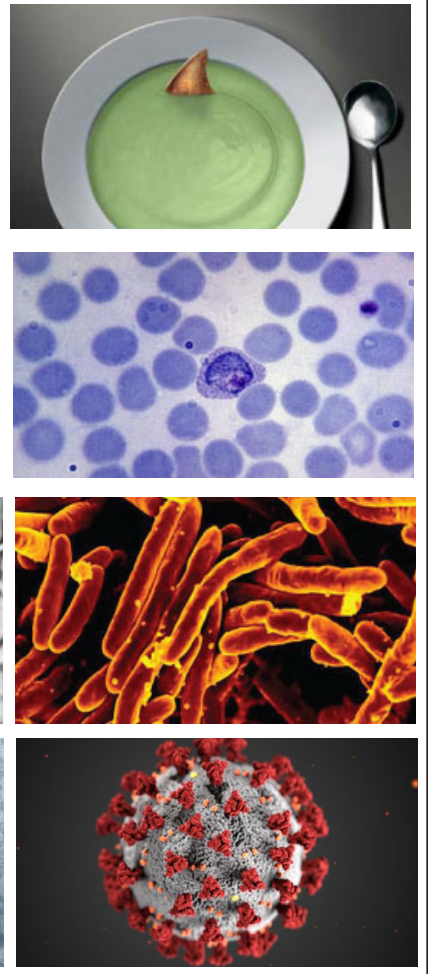

EID's spotlight topics highlight the latest articles and information on emerging infectious disease topics in our global community

https://wwwnc.cdc.gov/eid/page/spotlight-topics 